\title{
Determination of Magnesium Valproate and Its Process Related Impurities by Ultraperformance Liquid Chromatography
}

\author{
Rakshit Thakkar, Hitesh Saravaia, Madhavi Patel, and Anamik Shah \\ National Facility for Drug Discovery through NCEs Development \& Instrumentation Support to SMPEs, \\ Department of Chemistry, Saurashtra University, Rajkot, Gujarat 360005, India \\ Correspondence should be addressed to Rakshit Thakkar; rakshitthakkar_rt@yahoo.com
}

Received 23 March 2014; Revised 27 April 2014; Accepted 28 April 2014; Published 14 July 2014

Academic Editor: Luigi Janiri

Copyright (C) 2014 Rakshit Thakkar et al. This is an open access article distributed under the Creative Commons Attribution License, which permits unrestricted use, distribution, and reproduction in any medium, provided the original work is properly cited.

\begin{abstract}
A selective ultraperformance liquid chromatographic (UPLC) method for the determination of magnesium valproate and its process related impurities has been developed. The method includes reversed-phase Acquity BEH $\mathrm{C}_{18}$ column with $100 \mathrm{~mm} \times 2.1 \mathrm{~mm}$ i.d. and $1.7 \mu$ particle size. The mobile phase consists of acetonitrile and $5 \mathrm{mM}$ ammonium dihydrogen orthophosphate with $\mathrm{pH}=3.0$ at $45: 55$ isocratic elution. The flow rate was set at $0.3 \mathrm{~mL} / \mathrm{min}$ and UV detection was performed at $215 \mathrm{~nm}$. A system suitability test (SST) was developed to govern the quality of the separation. The developed method has been validated further with respect to linearity, accuracy, precision, selectivity, LOD, LOQ, and robustness. Different batches of samples were examined using this method; the method proved to be successful when applied to analyze a marketed magnesium valproate formulation.
\end{abstract}

\section{Introduction}

Magnesium valproate is chemically known as magnesium 2-propylpentanoate. Magnesium valproate is an anticonvulsant used in the treatment of epilepsy and bipolar disorder, as well as other psychiatric conditions requiring the administration of a mood stabilizer [1-6]. Chemical structures of magnesium valproate and four of its process related impurities are given in Figure 1. To our knowledge, there is no paper describing an ultraperformance liquid chromatographic (UPLC) method that allows the separation of magnesium valproate and its impurities in bulk drugs. Some articles exist on isocratic liquid chromatographic methods for the determination of magnesium valproate $[7,8]$. However, these isocratic methods use short columns and are suitable for assay only since they focus on the main peak. The gas chromatographic methods and colorimetric methods are also in literature [9-11]. The methods for determination of valproic acid and sodium valproate are also useful for achieving the best results in this work [12-14]. Some of the bioanalytical methods are also available in literature [15-21]. Applying the above methods for the separation of impurities in a bulk magnesium valproate sample gives poor separation. Therefore, an attempt was made to develop a new, rapid, and sensitive method for the determination of magnesium valproate and its process related impurities. To access the reproducibility and wide applicability of the developed method, it was validated as per international code of harmonization norm, which is also mandatory [22]. This paper also deals with the validation of the developed UPLC method for the assay of magnesium valproate from its bulk and pharmaceutical dosage form.

\section{Material and Methods}

2.1. Chemicals and Reagents. Parth Laboratories Pvt. Ltd. (Rajkot, India) has provided magnesium valproate and its process related impurities working standards and samples. Ammonium dihydrogen orthophosphate for HPLC, orthophosphoric acid (HPLC grade), and HPLC grade acetonitrile were purchased from Spectrochem Pvt. Ltd. HPLC grade water used was purified by Milli-Q Elix-3 water purification system. 


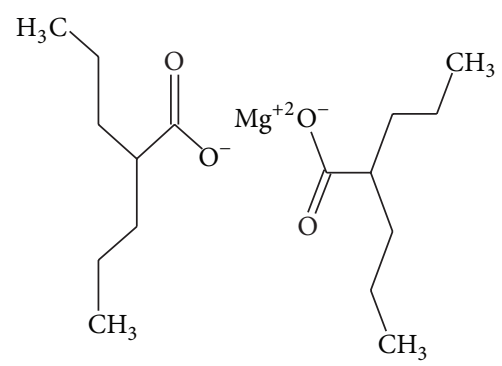

Magnesium valproate<smiles>CCCCC(=O)O</smiles>

Pentanoic acid

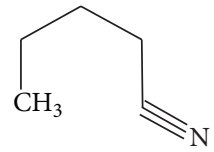

Valeronitrile<smiles>CCCC(CC)C(=O)O</smiles>

2-Ethyl pentanoic acid<smiles>CCCC(C(=O)O)C(C)C</smiles>

2-(1-Methyl, ethyl)pentanoic acid

FIGURE 1: Chemical structure of magnesium valproate and its process related impurities.

2.2. Instrumentation. The Waters Acquity UPLC chromatographic system was used to perform development and validation. This system consists of a binary solvent manager, multiple wavelength ultraviolet detector, sample manager, and column oven connected to a multi-instrument data acquisition and processing system Empower 2.1 version. Sartorius microbalance and Equiptronics branded balance and heating oven was used for the weighing and heating purpose while Spinco ultrasonic bath was used for degassing purpose.

2.3. Method Development. Analytical method development consists of the following steps which can be bound up by the literature survey, previous experience, and chemical nature of the reagents used in the development.

2.4. Mobile Phase Selection. On the basis of literature survey, several exploratory runs have been performed but initially proper selectivity and resolution between the drug substance and its impurities were not achieved. After furnishing more importance to the literature, it was concluded that since one impurity specifically 2-(1-ethyl-methyl)pentanoic acid is a structural isomer of the drug component (valproic acid), the $5 \mathrm{mM}$ ammonium dihydrogen orthophosphate with $\mathrm{pH}=3.0$ has given the maximum resolution with acetonitrile as organic component at isocratic elution, $55: 45$, v/v.

2.5. Column Selection. Column selection is the most important part in the method development. In this case most suitable column chemistry was bridge ethyl hybrid (BEH) $\mathrm{C}_{18}$ among the column chemistry available with us. Acquity $\mathrm{BEH} \mathrm{C}_{18}(100 \mathrm{~mm} \times 2.1 \mathrm{~mm}$ i.d., $1.7 \mu$ particle size $)$ has given the best outcomes. The resolution between the 2-(1ethyl-methyl)pentanoic acid and the valproate salt was not achieved by the other columns.

2.6. Detection Wavelength Selection. The standard solution was screened over $190 \mathrm{~nm}$ to $400 \mathrm{~nm}$ using the advantage of photodiode array detector. On the basis of peak absorption maxima and peak purity index, the $215 \mathrm{~nm}$ was decided as the detection wavelength which has provided the maximum chromatographic compatibility to the method.

2.7. Mobile Phase Preparation. The mobile phase consists of acetonitrile: $5 \mathrm{mM}$ ammonium dihydrogen orthophosphate $(\mathrm{pH}=3.0)(45: 55)$ was prepared by dissolving 575 milligram of ammonium dihydrogen orthophosphate for HPLC in $1000 \mathrm{~mL}$ ultrapure (HPLC grade) water; then the $\mathrm{pH}$ of the buffer solution was adjusted up to 3.0 using $0.1 \%$ orthophosphoric acid solution. This was further mixed with acetonitrile by mentioned ratio and filtered through $0.22 \mu \mathrm{n}$ filter followed by degassing in ultrasonic bath for $20 \mathrm{~min}$.

2.8. Standard Solution Preparation. Magnesium valproate and its related impurities working standard solution containing $200 \mu \mathrm{g} / \mathrm{mL}$ were prepared in a $100 \mathrm{~mL}$ volumetric flask by dissolving $20.0 \mathrm{mg}$ each in $25 \mathrm{~mL}$ acetonitrile : water $(50: 50)$ and then diluting to volume with the same diluent. Further this was filtered through $0.22 \mu \mathrm{n}$ filter followed by degassing in ultrasonic bath for $20 \mathrm{~min}$. The chromatogram of working standard is given in Figure 2.

2.9. Sample Solution Preparation. Magnesium valproate and its related impurities sample (different batch) solution containing $200 \mu \mathrm{g} / \mathrm{mL}$ were prepared in a $100 \mathrm{~mL}$ volumetric 


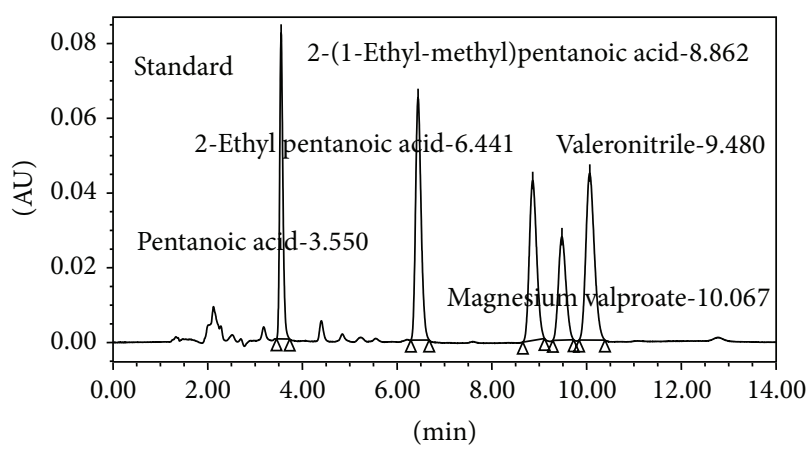

(a)

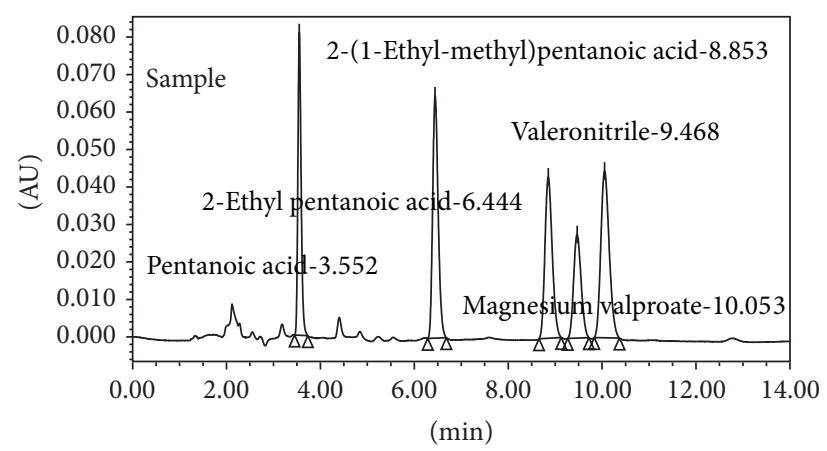

(b)

FIGURE 2: Chromatograms of working standard and sample solution.

TABLE 1: Chromatographic conditions of proposed analytical method.

\begin{tabular}{ll}
\hline Parameters & Optimum condition \\
\hline Mobile phase A & $5 \mathrm{mM}$ ammonium dihydrogen orthophosphate $(\mathrm{PH}=3.0)$ \\
Mobile phase B & acetonitrile $($ HPLC grade) \\
Column & Acquity BEH $\mathrm{C}_{18}(100 \mathrm{~mm} \times 2.1 \mathrm{~mm}$ i.d., $1.7 \mu$ particle size) \\
Flow rate & $0.3 \mathrm{~mL} / \mathrm{min}$ \\
Isocratic elution at & $55: 45, \mathrm{v} / \mathrm{v}$ \\
Detection & $215 \mathrm{~nm} \mathrm{UV}$ \\
Diluent & Acetonitrile : water $(1: 1)$ \\
Injection volume & $5 \mu \mathrm{L}$ \\
\hline
\end{tabular}

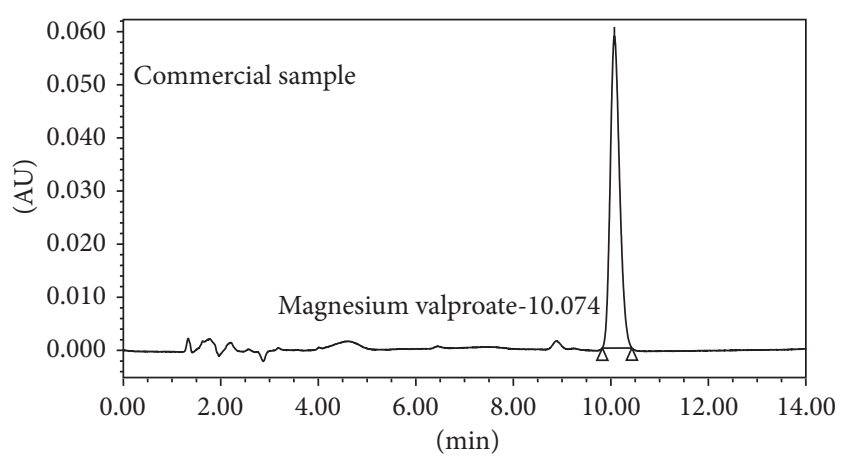

FIGURE 3: Chromatogram of commercial sample of magnesium valproate.

flask by dissolving $20 \mathrm{mg}$ each in $25 \mathrm{~mL}$ acetonitrile: water $(50: 50)$ and then diluting to volume with the same diluent. Commercially, magnesium valproate is available in $200 \mathrm{mg}$, $300 \mathrm{mg}$, and $500 \mathrm{mg}$ pharmaceutical dosage form. Average weight of the tablet was found by weighing 20 tablets and then it was dissolved and diluted to achieve the $200 \mu \mathrm{g} / \mathrm{mL}$ concentration. Further this was filtered through $0.22 \mu$ n filter followed by degassing in ultrasonic bath for $20 \mathrm{~min}$. The chromatogram of sample solution and commercial is shown in Figures 2 and 3, respectively.

\section{Results and Discussion}

With reference to the method development, chromatographic parameters used for method validation experiments are given in Table 1.

Method for the determination of magnesium valproate and its related impurities in bulk drug is further validated as per ICH Q2(R1) guideline [21]. Validation of analytical method was performed using magnesium valproate and its process related impurities working standard and sample batch drug substance.

The accuracy experiment was performed by recovery study at three levels, $150 \%, 100 \%$, and $50 \%$, of the standard concentration. The working standard of magnesium valproate and its related impurities were added to the samples and the recovery was calculated which was between 98 and $102 \%$; these were well within the acceptance criteria.

The method precision was assessed using multiple preparations of a single sample. Six different preparations of the same magnesium valproate and its related impurities sample, each $0.20 \mathrm{mg} / \mathrm{mL}$, were analyzed in triplicate on the same day. New solutions were prepared and analyzed on each of two successive days. The $\% \mathrm{RSD}$ values obtained for the peak areas of magnesium valproate, valeronitrile, pentanoic acid, 2-ethyl pentanoic acid, and 2-(1-methyl, ethyl)pentanoic acid were not more than 2.0. The intermediate precision study was performed using another Acquity $\mathrm{BEH} \mathrm{C}_{18}$ column $(100 \mathrm{~mm} \times$ $2.1 \mathrm{~mm}$ i.d., $1.7 \mu$ particle size). The $\% \mathrm{RSD}$ values were of the same magnitude as above. 


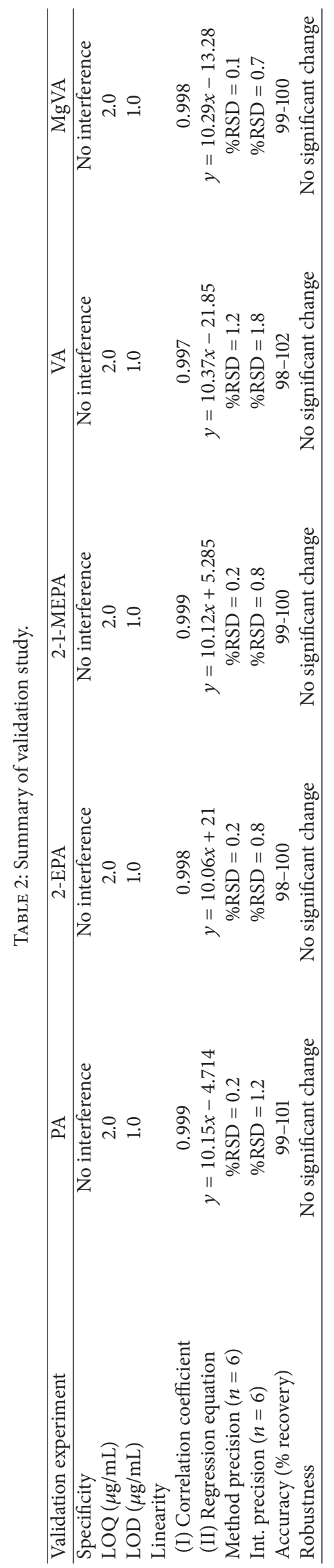


The linearity of the method was evaluated by analyzing eight solutions in the concentration ranges $50-350 \mu \mathrm{g} / \mathrm{mL}$ for each solution of magnesium valproate and its related impurities. The peak areas obtained from different concentrations of the drugs were used to calculate linear regression equations. These were $y=10.15 x-4.714, y=10.06 x+21, y=10.12 x+$ 5.285 , and $y=10.37 x-21.85$ with correlation coefficients of $R^{2}=0.999, R^{2}=0.998, R^{2}=0.999, R^{2}=0.997$, and $R^{2}=0.998$ for pentanoic acid, 2-ethyl pentanoic acid, 2-(1methyl, ethyl)pentanoic acid, valeronitrile, and magnesium valproate, respectively. The high values of the correlation coefficients were indicative of linear relationships between analyte concentration and peak area.

The limits of detection (LOD) and quantification (LOQ) were established by evaluating the minimum level at which the analytes could be readily detected and quantified with accuracy, respectively. The LOD and LOQ for each component were $1.0 \mu \mathrm{g} / \mathrm{mL}$ and $2.0 \mu \mathrm{g} / \mathrm{mL}$. The signal to noise ratio was more than 3 and 10 for LOD and LOQ, respectively.

The selectivity of the method was evaluated by injecting blank matrix, each individual impurity, magnesium valproate standard solution, and spiked solution to check the interference of the diluent as well as the standard solution on each other. The method was proved as highly selective that there was no interference on any component to others. The separation factor $(\alpha)$ was investigated for all the impurities, which found $0.33,0.64,0.88$, and 0.90 for pentanoic acid, 2-ethyl pentanoic acid, 2-(1-methyl, ethyl)pentanoic acid, and valeronitrile, respectively.

The influence of five chromatographic parameters $(k)$ on the separation was investigated. The parameters examined were the amount of acetonitrile in mobile phase, the $\mathrm{pH}$ of the ammonium dihydrogen orthophosphate solution, and the amount of ammonium dihydrogen orthophosphate solution in the mobile phase. No such impact of the small changes on the above parameters was observed which suggest that the method is highly robust.

The developed UPLC method shows a good separation of magnesium valproate to its impurities. The robustness study indicated that mainly the $\mathrm{pH}$ of the ammonium dihydrogen orthophosphate solution should be monitored carefully to ensure the best separation as this has a significant effect on the separation. The method is found to be selective, precise, sensitive, and linear, which is also proved from the summary of method validation (Table 2). The method can be used for the determination of magnesium valproate and the identification of the impurities present in the pharmaceutical dosage form.

\section{Conflict of Interests}

The authors declare that there is no conflict of interests regarding the publication of this paper.

\section{Acknowledgments}

The authors are grateful to the National Facility for Drug Discovery through NCEs Development \& Instrumentation
Support to SMPEs, Department of Chemistry at Saurashtra University (Rajkot, India), for providing the state-of-theart analytical facilities. They are thankful to UGC and DST (DPRP Programme), Government of India, for providing financial assistance in terms of meritorious research fellowship and research assistantship. They are also thankful to the M/s Parth Laboratories Pvt. Ltd. (Rajkot, India) for providing working standards and samples.

\section{References}

[1] K. K. Borowicz, Z. Kimber-Trojnar, N. Ratnaraj, P. N. Patsalos, J. J. Luszczki, and S. J. Czuczwar, "Isobolographic analysis of interactions between losigamone and conventional antiepileptic drugs in the mouse maximal electroshock model," European Neuropsychopharmacology, vol. 17, no. 2, pp. 94-101, 2007.

[2] G. Gobbi and L. Janiri, "Sodium- and magnesium-valproate in vivo modulate glutamatergic and GABAergic synapses in the medial prefrontal cortex," Psychopharmacology, vol. 185, no. 2, pp. 255-262, 2006.

[3] K. K. Borowicz, B. Piskorska, J. Łuszczki, and S. J. Czuczwar, "Influence of SIB 1893, a selective mGluR5 receptor antagonists, on the anticonvulsant activity of conventional antiepileptic drugs in two models of experimental epilepsy," Polish Journal of Pharmacology, vol. 55, no. 5, pp. 735-740, 2003.

[4] R. Canger and L. Guidolin, "Clinical efficacy and tolerability of magnesium valproate as monotherapy in patients with generalised or partial epilepsy: a nonblinded study of 320 patients," Clinical Drug Investigation, vol. 20, no. 4, pp. 215-221, 2000.

[5] M. Onofrj, U. Colangelo, G. Malatesta, and M. Di Giovanni, "Comparative study between sodium valproate and magnesium valproate in the treatment of patients with epileptic seizures," Rivista di Neurologia, vol. 58, no. 6, pp. 223-230, 1988.

[6] M. Lalic, J. Cvejic, J. Popovic et al., "Lamotrigine and valproate pharmacokinetics interactions in epileptic patients," European Journal of Drug Metabolism and Pharmacokinetics, vol. 34, no. 2, pp. 93-99, 2009.

[7] R. Hao, C. Yan, and Y. Liu, "Determination of magnesium and sodium valproate in serum by high performance liquid chromatography after precolumn derivatization," Yaowu Fenxi Zazhi, vol. 17, pp. 172-174, 1997.

[8] A. Balbi, E. Sottofattori, M. Mazzei, and W. G. Sannita, "Study of bioequivalence of magnesium and sodium valproates," Journal of Pharmaceutical and Biomedical Analysis, vol. 9, no. 4, pp. 317321, 1991.

[9] M. Hu, S. Huang, and B. Xiao, "Determination of magnesium valproate in serum by gas chromatography," $\mathrm{Se} P u$, vol. 5, pp. 362-364, 1987.

[10] W. Czarnecki and B. Hałczyńska, "Colorimetric determination of valproic acid and its salts," Acta Poloniae Pharmaceutica: Drug Research, vol. 56, no. 5, pp. 353-355, 1999.

[11] M. A. Ambasana, H. O. Kaila, R. S. Thakkar, H. T. Saravaia, and A. K. Shah, "Validation of an analytical method for assay of magnesium valproate by gas chromatography," International Journal of ChemTech Research, vol. 3, no. 1, pp. 342-347, 2011.

[12] X. Zhan and M. Xu, "Determination of sodium valproate in human serum by HPLC," Zhongguo Yaoye, vol. 18, pp. 25-26, 2009. 
[13] Y. X. Lin and H. C. Su, "RP-HPLC determination of valproate concentration in serum," Zhongguo Jiceng Yiyao, vol. 14, pp. 1300-1301, 2007.

[14] C. A. Lau-Cam and R. W. Roos, "HPLC method with precolumn phenacylation for the assay of Valproic acid and its salts in pharmaceutical dosage forms," Journal of Liquid Chromatography \& Related Technologies, vol. 20, pp. 2075-2087, 1997.

[15] M. Nakajima, A. Sato, and K. Shimada, "Determination of serum valproate by high-performance liquid chromatography using fluorescence labeling with 9-aminophenanthrene," Analytical Sciences, vol. 4, no. 4, pp. 385-388, 1988.

[16] T. Maeda, F. Miyagawa, M. Nakamura, and M. Saito, "Determination of antiepileptic drugs by high performance liquid chromatography," Sei Marianna Ika Daigaku Zasshi, vol. 10, pp. 153-161, 1982.

[17] Y. Zhong, Z. Jiao, and Y. Yu, "Simultaneous determination of mycophenolic acid and valproic acid based on derivatization by high-performance liquid chromatography with fluorescence detection," Biomedical Chromatography, vol. 20, no. 4, pp. 319326, 2006.

[18] S. Hara, M. Kamura, K. Inoue, M. Fukuzawa, N. Ono, and T. Kuroda, "Determination of valproic acid in human serum by high-performance liquid chromatography with fluorescence detection," Biological and Pharmaceutical Bulletin, vol. 22, no. 9, pp. 975-977, 1999.

[19] E. Bousquet, V. Cavrini, R. Gatti, and A. Spadaro, "Determination of valproic acid salts in pharmaceutical preparations by high performance liquid chromatography with coulometric electrochemical detection," Journal of Liquid Chromatography and Related Technologies, vol. 21, no. 18, pp. 2873-2886, 1998.

[20] H. Liu, L. J. Forman, J. Montoya, C. Eggers, C. Barham, and M. Delgado, "Determination of valproic acid by high-performance liquid chromatography with photodiode-array and fluorescence detection," Journal of Chromatography: Biomedical Applications, vol. 576, no. 1, pp. 163-169, 1992.

[21] K. Kondo, M. Nakamura, R. Nishioka, and S. Kawai, "Direct method for determination of Valproic acid in serum by high performance liquid chromatography," Analytical Sciences, vol. 1, pp. 385-387, 1985.

[22] ICH-Q2(R1), International Conference on Harmonization validation of analytical procedures: text and methodology, 2005. 

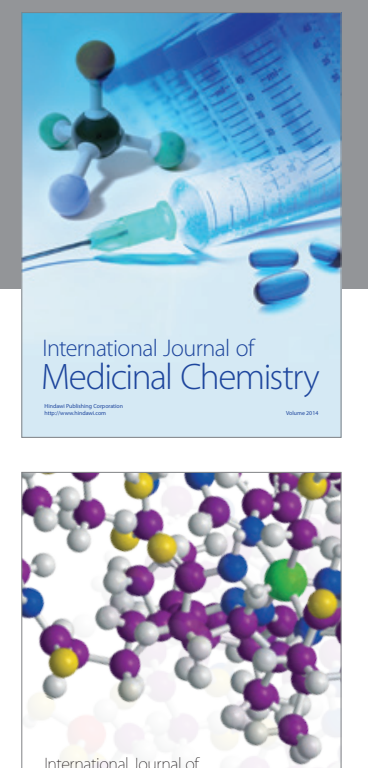

\section{Carbohydrate} Chemistry

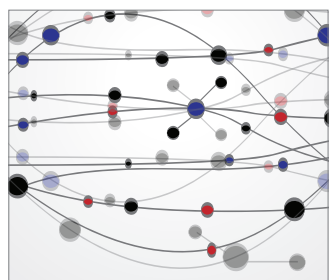

The Scientific World Journal
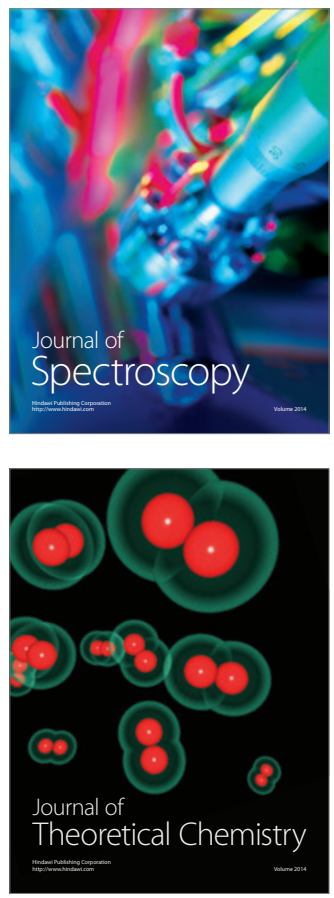
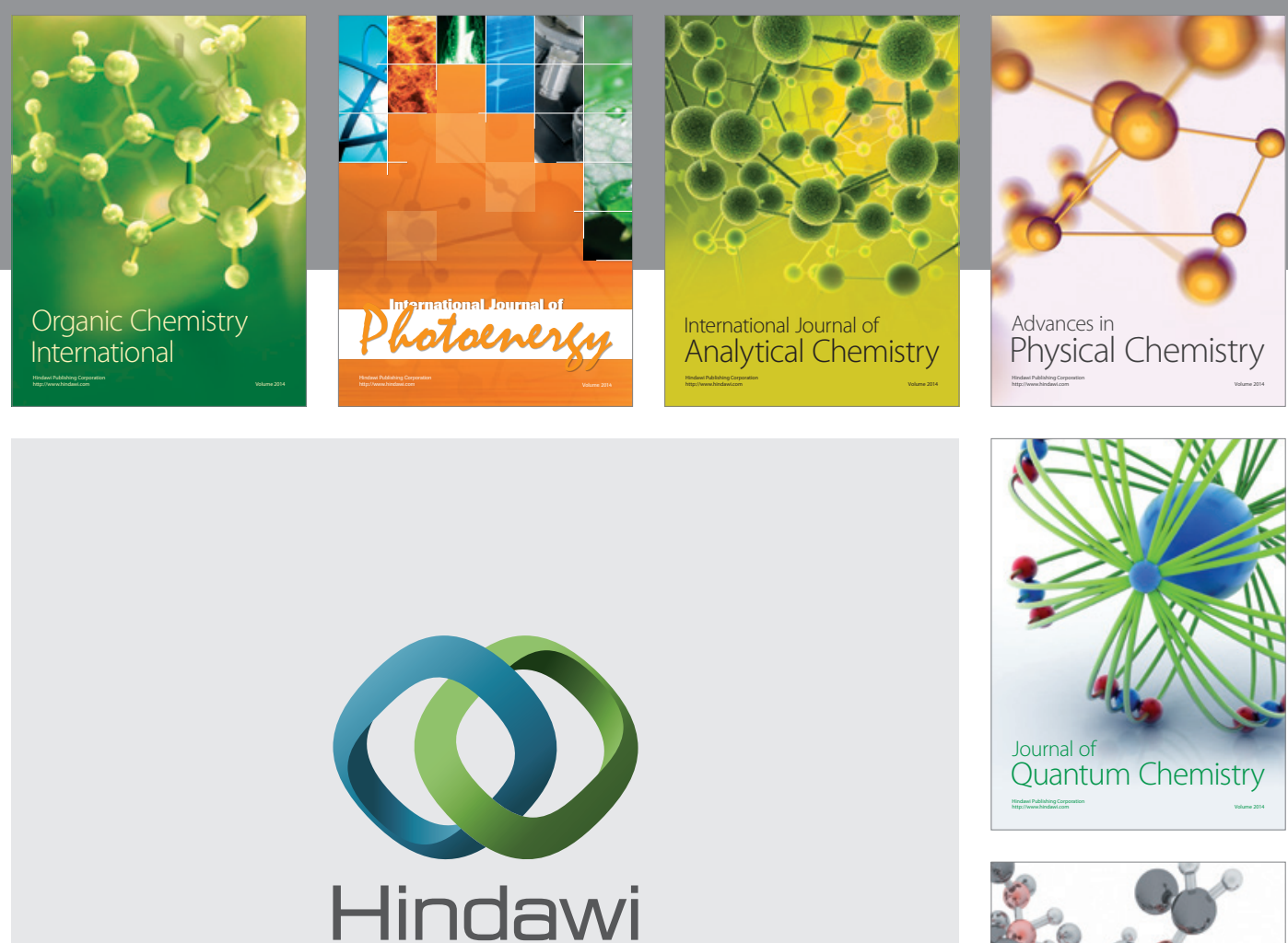

Submit your manuscripts at

http://www.hindawi.com

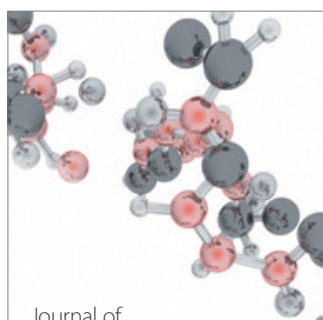

Analytical Methods

in Chemistry

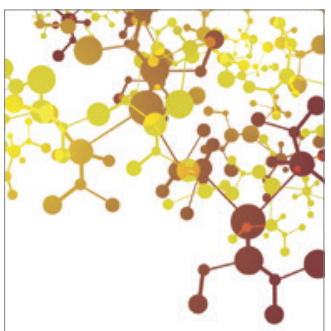

Journal of

Applied Chemistry

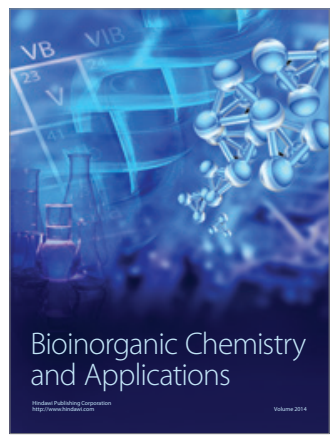

Inorganic Chemistry
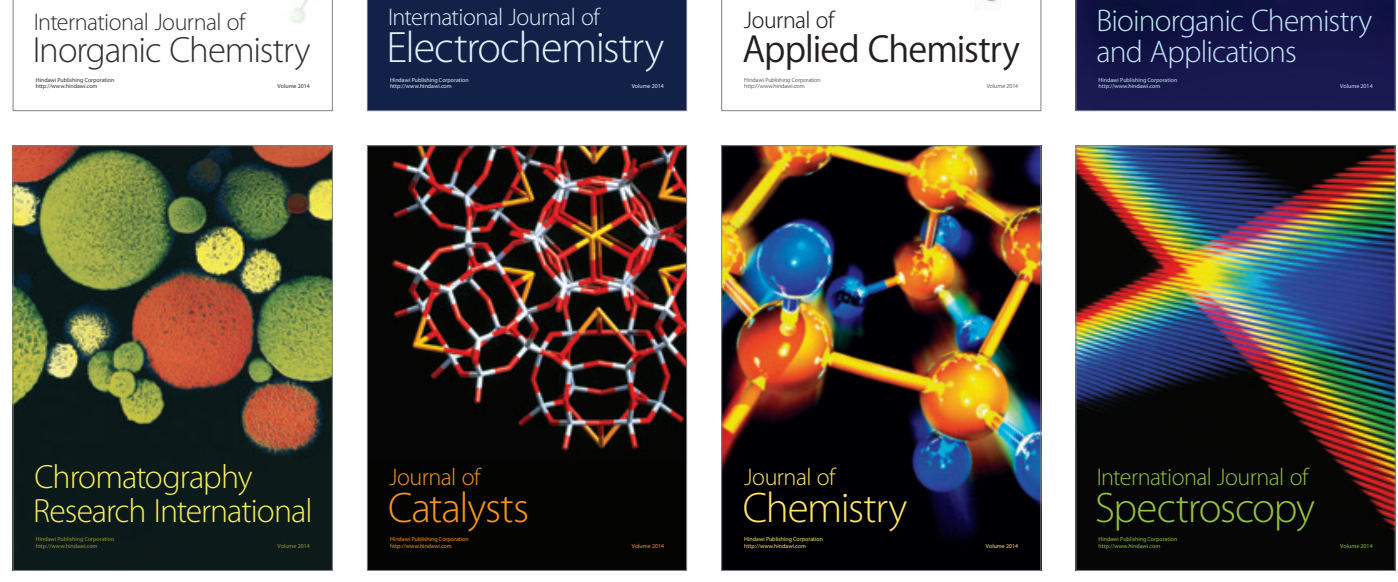